\title{
Microstrip Antenna Design With Defected Ground Structure
}

\author{
Naheed Anjum Khan ${ }^{1}$, Bharati A.Singh ${ }^{2}$ \\ ${ }^{1}$ (P.G. student, Electronics \& Telecommunication dept, , K.J. Somaiya College of Engineering, \\ Mumbai University, India) \\ ${ }^{2}$ (Associate Professor, Electronics \& Telecommunication dept., K.J. Somaiya College of Engineering, \\ Mumbai University, India)
}

\begin{abstract}
This paper presents the bandwidth enhancement of co-axial fed truncated microstrip antenna using dumbbell shaped defected ground structure (DGS). The proposed antenna resonating at $5.4 \mathrm{GHz}$ finds application in wireless local area networks in wireless communication systems. To make the proposed antenna more efficient, the designed parameters of the antenna have been optimized and its characteristics are investigated using IE3D software.
\end{abstract}

Keywords: Bandwidth (BW),Dumbbell shaped defected ground structure (DGS),Rectangular microstrip patch antenna(RMSA), Return loss (RL),Voltage wave standing ratio(VSWR).

\section{INTRODUCTION}

Communication plays a very important role in today's world as the switching of communication systems from "wired to wireless" has been very rapid. Antenna is one of the most important elements of wireless communication systems allowing the tranmission and reception of electromagnetic waves in free space. The design of an efficient, small size antenna providing large operating bandwidth for recent wireless applications is a major challenge. Thus, antenna design has become one of the most important and demanding aspect in the field of wireless communication.

One of the most popular and frequently used antenna in this field is microstrip patch antennas. Microstrip antennas are widely used for its low profile, easy manufacturability, simple structure, low cost and omni directional radiation patterns[1].These features provides a great advantage over the traditional ones. But the drawback of this kind of antenna also sometimes confine their applications, especially the narrow bandwidh. So, there have been inventions of new technologies to overcome these shortcomings. One such technique that can be used to overcome these limitations is Defected Ground Structure (DGS). Recently there has been an increasing in the use of DGSs for performance enhancement of microstrip antennas. These structures are realized by etching off a simple shape defect from the ground plane of microstrip patch antenna [2].

A truncated microstrip antenna with dumbbell shaped DGS is proposed. The bandwidth of the original microstrip antenna is increased due to the implementation of DGS in the ground plane. Also, there is reduction in the size of the antenna proposed as compared to the original antenna. By varying the various dimensions of the defect, the desired resonance frequency can be achieved [3]. The effect of dumbbell shaped DGS, onto the size reduction of a microstrip antenna along with improved parameter performance is investigated

Section 2 provides the design methodology of microstrip patch antenna at $5.4 \mathrm{GHz}$ whereas section 3 shows the simulation results obtained for RMSA and truncated MSA. In section 4, implementation of DGS in the ground plane is explained along with the help of simulation results. Finally, a conclusion is made stating the improvisation in bandwidth.

\section{ANTENNA DESIGN}

Rectangular microstrip antenna (RMSA) is the simplest configuration of the microstrip patch. It consists of a rectangular patch on upper surface and co-axial feed on the lower surface as shown in fig.1. The main advantage of co-axial feeding method is that the feed point can be placed at any location desired in the patch so as to match with its input impedance.This feeding technique is easy to fabricate and has low spurious radiation [1]. 


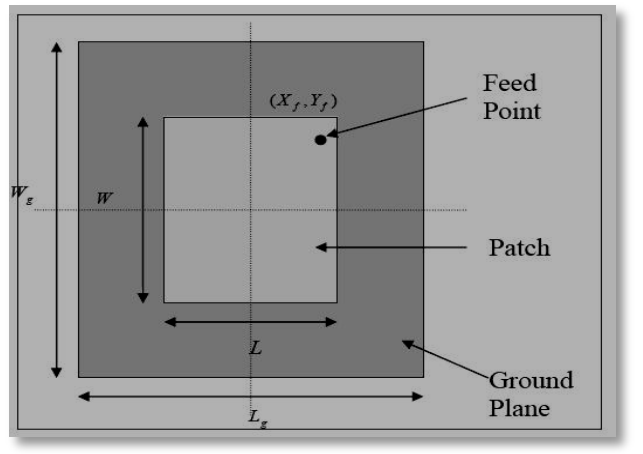

Fig1: Co-axial fed RMSA [4]

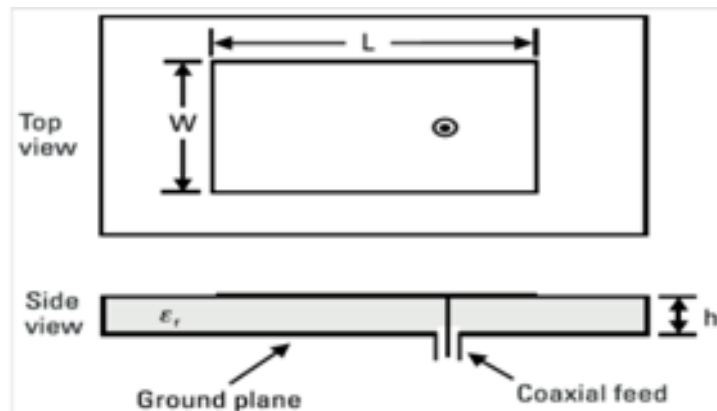

Fig 2: Top view of RMSA

\subsection{Design Methodology}

\subsubsection{Design Specifications}

Frequency of operation $\left(f_{0}\right)$ :The resonant frequency selected for the proposed antenna for WLAN applications is $5.4 \mathrm{GHz}$.

Dielectric constant of the substrate $(€ \mathrm{r})$ : Substrate used is FR4 glass epoxy and its dielectric constant is 4.3 and loss tangent 0.001 .

Height of the antenna (h): For the antenna to be used for WLAN applications, it is necessary that the antenna is light in weight and not bulky. Hence, height is selected accordingly as $1.59 \mathrm{~mm}$.

\subsubsection{Design Procedure}

Using the design specifications along with the equations obtained from transmission line model of analysis [4], the dimensions of the microstrip patch antenna can be calculated as explained below:

Step 1: For efficient radiation, the width is given as:

$\mathrm{W}=\mathrm{c} /\left(2 \mathrm{f}_{0} \sqrt{ }((€ \mathrm{r}+1) / 2)\right)=17.06 \mathrm{~mm}$

Step 2: Calculation of effective dielectric constant.

$\epsilon_{\text {reff }}=((€$ reff +1$) / 2)+\left[((€\right.$ reff-1 $\left.) / 2)(1+12 \mathrm{~h} / \mathrm{W})^{-1 / 2}\right]$

$$
=3.78 \mathrm{~mm}
$$

Step 3: Calculation of effective length of the patch:

$\mathrm{L}_{\text {eff }}=\mathrm{c} /\left(\mathrm{f}_{0} \sqrt{ } €_{\mathrm{reff}}\right)=14.28 \mathrm{~mm}$

Step 4 : Calculation of length extension:

$\Delta \mathrm{L}=0.412 \mathrm{~h} \frac{(\text { Ereff }+0.3)\left(\frac{\mathrm{W}}{\mathrm{h}}+0.264\right)}{(\text { Ereff- } 0.258)\left(\frac{\mathrm{W}}{\mathrm{h}}+0.8\right)}=0.7108 \mathrm{~mm}$

Step 5 : Calculation of actual length of patch:

$\mathrm{L}=\mathrm{L}_{\text {eff }}-2 \Delta \mathrm{L}=12.86 \mathrm{~mm}$

Step 6 : Calculation of ground plane dimensions:

The transmission line model is applicable to infinite ground planes only. However, for practical considerations, it is essential to have a finite ground plane. It has been shown that similar results for finite and infinite ground plane can be obtained if the size of the ground plane is greater than the patch dimensions by approximately six times the substrate thickness all around the periphery [5].Hence, for this design, the ground plane dimensions would be given as : $\mathrm{L}_{\mathrm{g}}=6 \mathrm{~h}+\mathrm{L}=22.4 \mathrm{~mm}, \mathrm{~W}_{\mathrm{g}}=6 \mathrm{~h}+\mathrm{W}=26.6 \mathrm{~mm}$

Step 7 : Determination of feed point location $\left(\mathrm{X}_{\mathrm{f}}, \mathrm{Y}_{\mathrm{f}}\right)$

As shown in fig 2, the center of the patch is taken as the origin and the feed point location is given by coordinates $\left(\mathrm{X}_{\mathrm{f}}, \mathrm{Y}_{\mathrm{f}}\right)$. The feed point must be located at that point on the patch, where the input impedance is 50 ohms for center frequency [1]. Hence, a trial and error method is used to locate the feed point. For different locations of the point, the return loss (RL) is compared and that feed point is selected where the RL is most negative.The optimum feed point selected for this design for $\mathrm{f}_{\mathrm{o}}=5.4 \mathrm{GHz}$ is $\left(\mathrm{X}_{\mathrm{f}}, \mathrm{Y}_{\mathrm{f}}\right)=(-4,0)$. 


\section{SIMULATION RESULTS}

The software used to perform all simulations is Zealand Inc's IE3D Version 12.23. IE3D is a full-wave electromagnetic simulator [6]. As shown in fig.4, return loss obtained is $-13.29 \mathrm{~dB}$ at $5.374 \mathrm{GHz}$. This frequency is near to the frequency of operaton, $5.4 \mathrm{GHz}$ and hence is considered. VSWR obtained is 1.55 which is in acceptable range $(\leq 2)$.

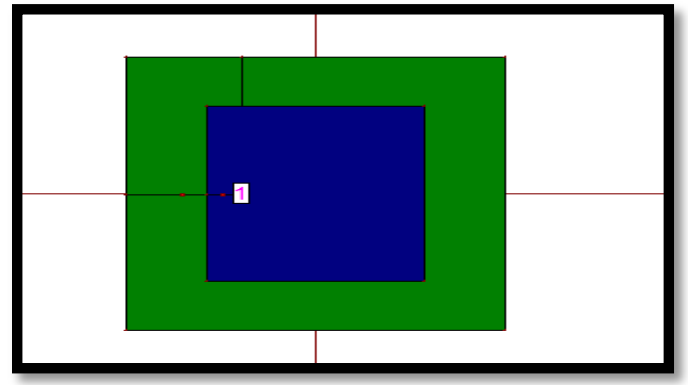

Fig 3 : Structure of RMSA designed using IE3D

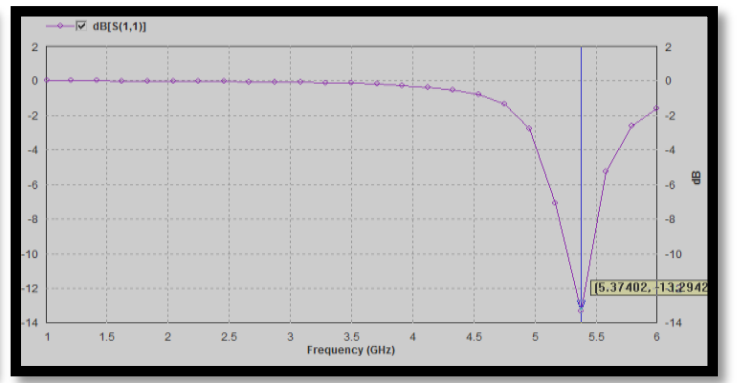

Fig 4 : RL plot of RMSA

The bandwidth of RMSA is calculated by observing the S11 graph. As shown in figure.5 below, the bandwidth obtained is $195.6 \mathrm{MHz}$. This bandwidth is increased by implementing DGS which is explained further.

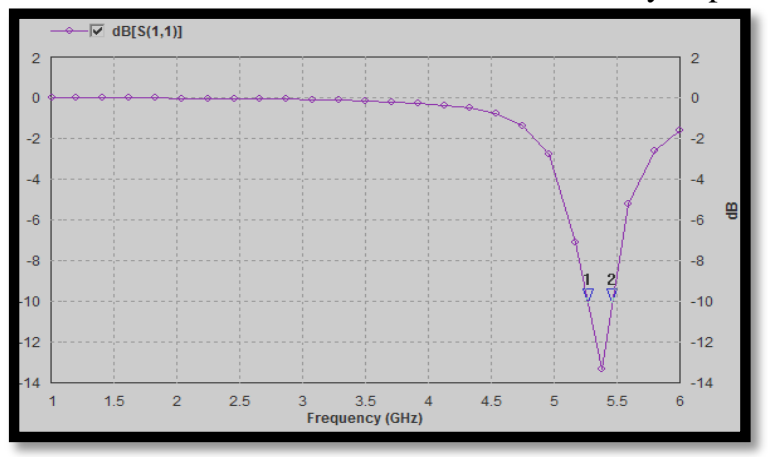

\begin{tabular}{|l|l|l}
\hline$\#$ & $X$ & $Y$ \\
\hline 1 & 5.26448 & -10.0288 \\
2 & 5.46009 & -10.0254 \\
\hline
\end{tabular}

Fig 5 : S11 graph of RMSA

Truncation is done at the corners of the RMSA as shown in the fig.6.A right angled triangle ( $2 \mathrm{~mm} \times 2 \mathrm{~mm})$ is removed from the corners of two opposite sides of the RMSA.Truncation helps in reducing the size of antenna [7].

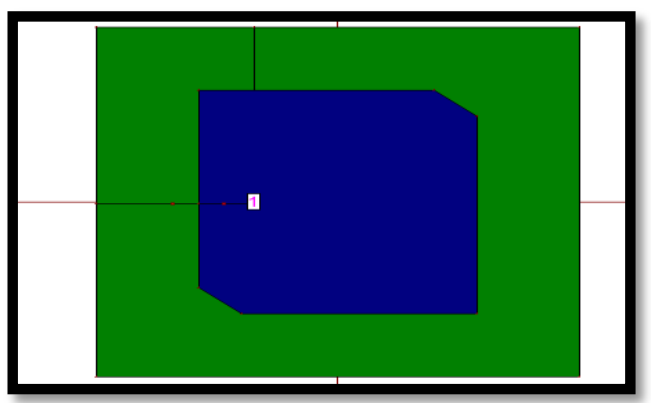

Fig 6:Structure of T-RMSA designed using IE3D

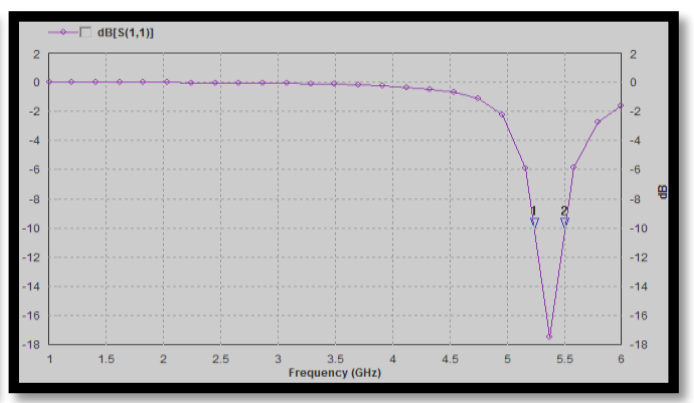

Fig 7: S11 graph of T-RMSA

The feed point is again obtained by iterative process as explained earlier in RMSA design procedure so as to get return loss to be most negative but at the same time bandwidth of the orginal RMSA should increase. So, accordingly the optimum feed point selected is $(-4,0)$ which is found to be the same as that of original RMSA.The truncated RMSA designed also resonates at the same frequency, $5.374 \mathrm{GHz}$ as that of original RMSA. It provides better performance results. The return loss has improved from $-13.29 \mathrm{~dB}$ to $-17.38 \mathrm{~dB}$. Also, the VSWR has reduced from 1.55 to 1.31 .

Our main concern is the bandwidth. It has been observed from the S11 graph of T-RMSA that bandwidth of the conventional MSA has increased from 195.6 to $265.38 \mathrm{MHz}$.(fig 7). 


\section{IMPLEMENTATION OF DGS}

The dimensions of the DGS are appropriately chosen as: $\mathrm{a}=3 \mathrm{~mm}, \mathrm{~b}=3 \mathrm{~mm}, \mathrm{~g}=1 \mathrm{~mm}, \mathrm{w}=2 \mathrm{~mm}$.

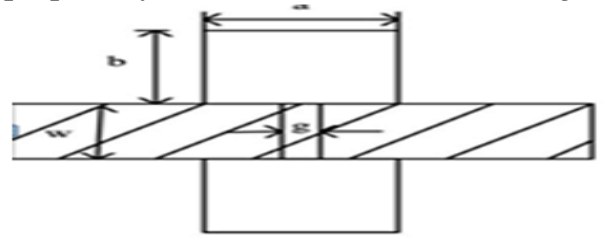

Fig 8:Dumbbell DGS etched in ground plane [8]

When this DGS is implemented in the ground plane of the T-RMSA, it is noticed that there is a shift in center frequency. So, to get the best possible result at center frequency, the antenna has been optimized by reducing the dimensions of the patch and the ground plane. Much improved results are obtained after optimization.The final dimension selected is: $\mathrm{L}=10 \mathrm{~mm}, \mathrm{~W}=14 \mathrm{~mm} \mathrm{Lg}=20 \mathrm{~mm}, \mathrm{Wg}=24 \mathrm{~mm}$

Feed point $\left(\mathrm{X}_{\mathrm{f}}, \mathrm{Y}_{\mathrm{f}}\right)=(-2,2)$
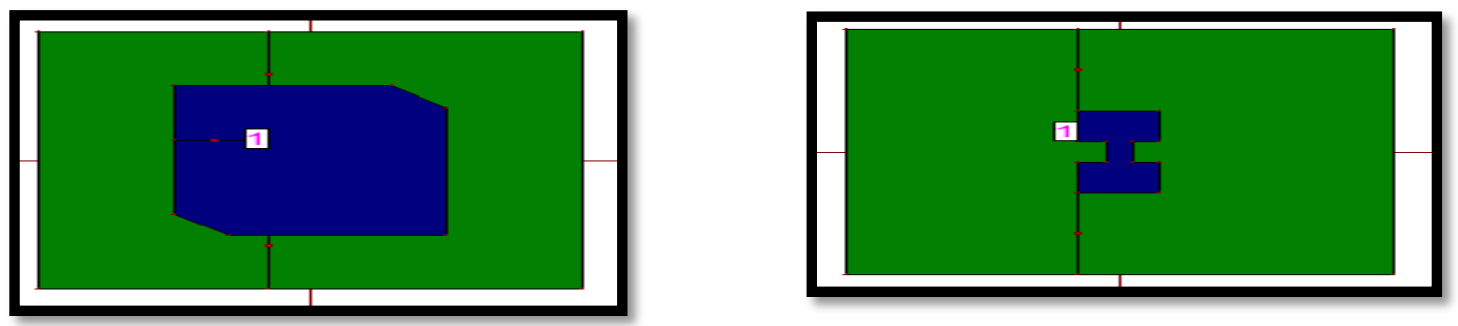

Fig 9: Structure of optimized T-RMSA with dumbbell shaped DGS in the ground plane

\begin{tabular}{|l|l|l|l|}
\hline $\begin{array}{l}\text { Performance } \\
\text { parameter }\end{array}$ & $\begin{array}{l}\text { Conventional } \\
\text { RMSA }\end{array}$ & $\begin{array}{l}\text { Truncated } \\
\text { RMSA (T- } \\
\text { RMSA) }\end{array}$ & $\begin{array}{l}\text { T-RMSA } \\
\text { with } \\
\text { dumbbell } \\
\text { DGS }\end{array}$ \\
\hline $\begin{array}{l}\text { Operating } \\
\text { frequency(GHz) }\end{array}$ & 5.375 & 5.375 & 5.375 \\
\hline Return loss(dB) & -13.23 & -17.38 & -12.4 \\
\hline VSWR & 1.55 & 1.31 & 1.63 \\
\hline Bandwidth(MHz) & 195.6 & 265.78 & 523.3 \\
\hline
\end{tabular}

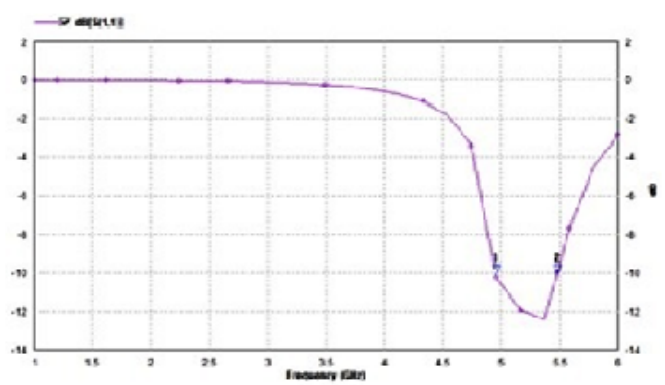

Fig 10 S . Trरrh of oytmized T.PMSA with dmbetl sbaped IGS

The bandwidth obtained is 523.3MHz.So the main intention of using DGS is satisfied. The Bandwidth of the original RMSA has improved significantly from 195.6 MHz to 523.3 MHz with DGS.(Refer Table 1).Also, after optimizing, the size of the original microstrip antenna has reduced.

\section{CONCLUSION}

The limitation of conventional MSA having narrow bandwidth has been overcomed by employing DGS technique.The bandwidth of truncated MSA designed to operate at $5.4 \mathrm{GHz}$ for WLAN applications has significantly broadened from $195.6 \mathrm{MHz}$ to $523.3 \mathrm{MHz}$. Also, there is reduction in the dimensions of the patch by $36.18 \%$ and ground plane by $19.44 \%$.

\section{ACKNOWLEDGEMENT}

I take this opportunity to express my profound gratitude and deep regards to my Guide Ms. Bharati Singh for her constant support and guidance. I would like to thank her for the valuable suggestions, constant encouragement and motivation without which this work would have not been possible. 


\section{REFERENCES}

[1]. C. A. Balanis, Antenna Theory: Analysis and Design( New York: Wiley, 1997)

[2]. Ashwini K. Arya, M. V. Kartikeyan, A .Patnaik, Gain Enhancement of Microstrip antenna using Dumbbell shaped Defected Ground Structure, International Journal of Research Engineering \& Technology, Vol.2,Issues 4,pp.184-188,July 2013.

[3]. Ashwini K. Arya, M. V. Kartikeyan, A .Patnaik, Defected Ground Structure in the perspective of Microstrip antenna, Progress in electromagnetic research,Vol.64, Issue5-6, pp.79-84, Oct 2010.

[4]. Girish Kumar and K.P.Ray, Broadband Microsrip antennas (Artech House Inc,2003.)

[5]. Preet kaur, Rajiv Nehra, Manjeet Kadian, Dr. Asok De, Dr.S. K. Agarwal, Design of improved performance of rectangular microstrip patch antenna using peacock and star shaped DGS, International Journal of Electronics Signals and Systems (IJESS), Vol-3, Issue-2, 2013.

[6]. Zealand's IE3D software,version 12.23.

[7]. Samarjeet Singh, Bhaskar Gupta ,Anil Kumar, Truncated Rectangular Microstrip Antenna for Wide band, International Journal of Science and Engineering, Vol 1, Issue 1-2013.

[8]. L.H .Weng, Y.C .Guo X.W .Shi, X .Q. Chen, An overview on defected ground structure, Progress in electromagnetic Research B, Vol.7, pp.173-189, July 2008. 